\title{
Comparison of approaches to deal with matrix effects in LC-MS/MS based determinations of mycotoxins in food and feed
}

\author{
N. Fabregat-Cabello ${ }^{1}$, P. Zomer ${ }^{2}$, J.V. Sancho ${ }^{1}$, A.F. Roig-Navarro ${ }^{1}$ and H.G.J. Mol ${ }^{2 *}$ \\ ${ }^{1}$ Research Institute for Pesticides and Water, Universitat Jaume I, 12071, Castellón, Spain \\ ${ }^{2}$ RIKILT Wageningen University and Research Centre, Akkermaalsbos 2, 6708 WB Wageningen, the \\ Netherlands; hans.mol@wur.nl
}

Received: 19 December 2014 / Accepted: 8 June 2015

(C) 2015 Wageningen Academic Publishers

\section{RESEARCH ARTICLE}

\begin{abstract}
This study deals with one of the major concerns in mycotoxin determinations: the matrix effect related to LC-MS/ MS systems with electrospray ionization sources. To this end, in a first approach, the matrix effect has been evaluated in two ways: monitoring the signal of a compound (added to the mobile phase) during the entire chromatographicrun, and by classical post-extraction addition. The study was focused on nine selected mycotoxins: aflatoxin B1, fumonisins B1, B2 and B3, ochratoxin A, deoxynivalenol, T-2 and HT-2 toxins and zearalenone in various sample extracts giving moderate to strong matrix effects (maize, compound feed, straw, spices). Although the permanent monitoring of a compound provided a qualitative way of evaluating the matrix effects at each retention time, we concluded that it was not adequate as a quantitative approach to correct for the matrix effect. Matrix effects measured by post-extraction addition showed that the strongest ion suppression occurred for the spices (up to -89\%). Five different calibration approaches to compensate for matrix effects were compared: multi-level external calibration using isotopically labelled internal standards, multi-level and single level standard addition, and two ways of singlepoint internal calibration: one point isotopic internal calibration and isotope pattern deconvolution. In general, recoveries and precision meeting the European Union requirements could be achieved with all approaches, with the exception of the single level standard addition at levels too close to the concentration in the sample. When an isotopically labelled internal standard is not available, single-level standard addition is the most efficient option.
\end{abstract}

Keywords: matrix effects, calibration, isotope dilution mass spectrometry, ion suppression, standard addition

\section{Introduction}

Mycotoxins are low-molecular-weight products of the secondary metabolism of some fungi, mainly from the genera Aspergillus, Penicillium and Fusarium, which are produced after a period of active growth or response to stress conditions (Bennett and Klich, 2003). These fungi grow mainly in cereals, but can also be found in fruits, spices, nuts or fodder. The interest of controlling the presence of the mycotoxins in food and animal feeds lies in the health problems they can induce due to their toxicity, including hepatic, gastrointestinal and carcinogenic diseases (Fung and Clark, 2004). For this reason maximum levels for food and feed have been established by the European Union (EC, 2002, 2006a,b, 2013).

In order to be able to determine the mycotoxins at the levels required by legislation, a wide range of analytical methods are developed each year (Berthiller et al., 2014; Shephard et al., 2013). For 
screening and semi-quantitative analysis, various immunochemical assays have been developed, including radio-immunoassays, enzymelinked immunosorbent assays (ELISA) and Sandwich ELISA, chemiluminiscent and fluorescent immunoassays, and lateral flow and flow-through immunoassays. For confirmatory and quantitative analysis, methods based on gas chromatography (GC) or highperformance líquid chromatography (HPLC) are commonly employed. In GC analysis, typically involving derivatisation, the mycotoxins are detected by electron capture detection, flame ionisation or mass spectrometry (MS). In HPLC the most common detectors are ultraviolet, diode array, fluorescence and MS (Pascale, 2009). A clear trend can be seen to develop multi-mycotoxin methods based on liquid chromatography coupled to tandem mass spectrometry (LC-MS/MS) for the simultaneous identification and quantification of the sought compounds (Beltran et al., 2013; Berthiller et al., 2014).

LC-MS/MS is one of the most powerful tools for orgànic compound analysis due to its high selectivity, sensitivity, and throughput. However, its quantitative performance can be affected by the matrix effect, especially when an electrospray ionisation source (ESI) is used.

The matrix effect is the alteration of the ionisation efficiency of a compound, due to the presence of substances coeluting with the target analyte (Taylor, 2005). Matrix effects can depend on source design and therefore differ from instrument to instrument. It can cause either an enhancement or suppression of the compound signal but the latter is more common (Furey et al., 2013). Consequently, it is necessary to test and study the matrix effect during the development and validation of each new method. The evaluation of the matrix effect can be performed mainly by two approaches: by post-extraction addition or by postcolumn infusion (Trufelli et al., 2011). The postextraction addition is based on the comparison between the peak area of a standard prepared in solvent and the area obtained after spiking an extract of a blank sample at the same concentration. In the case of post-column infusion the target compound is added to the eluent through a T-piece after the LC column. The signal of the target compound is monitored after injection of a blank sample extract. Response fluctuations of the target compound reflect the matrix effect.

A wide variety of strategies can be employed in order to overcome the matrix effect (Furey et al., 2013; Trufelli et al., 2011). The simplest possibility is a dilution of the sample extract in solvent, but since it diminishes the amount of analyte introduced in the system, this is only a viable option when the required limit of quantitation (LOQ) can still be achieved (Stahnke et al., 2012). In the same line, a low injection volume combined with a high flow rate can also decrease the matrix effect. Other options are a more exhaustive method development by the optimisation of chromatographic separation (avoiding compounds to coelute with the target analytes), improving sample clean-up and selective extraction. Measuring the analytes as negative ion can also reduce matrix effects. The main drawbacks of these approaches are that the total time for method development is considerably increased and that the method becomes less suitable for simultaneous determination of multiple mycotoxins with different physical-chemical properties.

An alternative to the elimination of the matrix effect is compensating for it by using certain calibration approaches. These include matrix-matched calibration, the Standard addition method, or the use of internal standards. Matrixmatched calibration requires the availability of noncontaminated material of the same composition as the sample and assumes that the matrix effect for a certain product is the same for different samples from that product which is not necessarily true (Matuszewski et al., 2003). In case different matrices are to be analysed, separate matrixmatched calibration standards need to be prepared for each matrix. This is also the case for standard addition approaches, but here the advantage is that no a priori knowledge of the sample composition is required which facilitates the analyses of composite products (e.g. multiingredient food products, compound feed).

Matrix-matched calibration using one individual model-sample is inferior to standard addition or the internal standardisation, where the compensation isphysically performed in each sample. In case of internal standardisation, as the use of a homologue cannot always compensate such variability, isotope labelled internal standard (ILIS) seems a better option. Among the available labelled internal 
standards, 13C-labelled are preferred over deuterated analogues in order to guarantee the perfect co-elution with their natural analogue. The use of ILIS is recognised as the most efficient way to compensate for matrix effects; however, availability and cost may límit the applicability in routine practise (Hewavitharana, 2011). Nevertheless, it has been shown that the additional cost can be as low as 2 euro per sample when the labels are added to a small volume of the final extract (Varga et al., 2012). A common approach is to add the label to the sample (or extract), and to the solventcalibration standards. The responses are normalised to that of the label and all samples can be quantified based on one solvent-based calibration curve. An alternative and even more straightforward way of using the isotope labels is one-point isotopic internal calibration (OPIC) often used as a compromise between the necessary calibration and workload (Peters and Maurer, 2007). Here the label is added to the sample (or extract) as well but no external calibration standards are used, i.e. the concentration in the sample is calculated based on the response of the label in that same sample and only one injection is required for both analysis of the sample and calibration. The isotope patern deconvolution (IPD) method also makes use of this way of calibration but using a different quantification procedure. This alternative approach is based on the determination of the molar fractions for each pure isotope pattern (natural abundance or labeled) contributing to the isotope patern observed in the mixture (spiked sample) by multiple linear regression in which a least square fitting can be applied. A simple equation is employed for the determination of the concentration of the analyte as the ratio of molar fractions is equal to the ratio of molar concentrations in the mixture. (Castillo et al., 2013; Gonzalez-Antuna et al., 2013).

An interesting and completely different approach that would eliminate the need for matrix-matching, standard addition, and isotope labels, is the use of the signal suppression (or enhancement) measured for one specific 'matrix-marker' substance monitored throughout the chromatographic run, to compensate for the matrix effect. This idea from Stahnke et al. (2009) relies on their observation that different compounds experience the same matrix effect at the same retention time.

This article reports on a comparative study of diferent strategies to account for matrix effects in LCESI-MS/MS. First the applicability of the approach proposed by Stahnke et al. (2009) to mycotoxins in highly complex matrices was investigated. Subsequently, we compared the following calibration approaches to compensate for matrix effects with respect to accuracy and efficiency: multi-level external calibration using isotopically labelled internal standards (IL-IS), the standard addition method (multi-level and single level), and two single-injection methods (OPIC and IPD). This was done for nine mycotoxins in five matrices of increasing complexity.

As far as we know, the comparison of different methodologies of matrix effect compensation in mycotoxin determination has only been recently evaluated in ochratoxin A (OTA) in grapes, musts and wines by stable isotope dilution assay and diastereomeric dilution assay methods (Roland et al., 2014).

\section{Materials and methods}

\section{Reagents and materials}

HPLC grade solvents methanol and acetonitrile were purchased from Biosolve (Valkenswaard, the Netherlands). Ultra-pure water was obtained from a Milli-Q System (Millipore Co., Bedford, MA, USA). Formic acid (>98\% purity), ammonium formate (>99\%), ammonium acetate (>99\%) and $13 \mathrm{C3}$ caffeine (>99\%) were obtained from Sigma- Aldrich (Zwijndrecht, the Netherlands) and carbendazim and chlormequat from Dr. Ehrenstorfer (Augsburg, Germany).

Biopure ${ }^{\circledR}$ mycotoxin standard solutions of unlabelled HT-2 and T-2 toxins in acetonitrile, uniformly [13C]- labelled (U-labelled) compounds aflatoxin B1 (AFB1), deoxynivalenol (DON), T-2 and HT-2 toxins (T-2 and HT-2), ochratoxin A (OTA) and zearalenone (ZEA) in acetonitrile and fumonisins B1, B2 and B3 (FB1, FB2 and FB3) in acetonitrile:water were purchased from Romer Labs Diagnostic GmbH (Tulln, Austria). FB3 standard solution in acetonitrile:water was acquired from PROMEC Unit (Medical Research Council, Tygerberg, South Africa). The other unlabelled mycotoxins standards were 
supplied by Sigma-Aldrich: FB1, FB2, DON, OTA and ZEA as a pure solid (purity higher than 98\%) and AFB1 in an acetonitrile solution. Individual stock solutions of fumonisins were prepared in acetonitrile:water (1:1), DON, T-2 and HT-2, OTA and ZEA solutions were prepared in acetonitrile.

The stocks of the unlabelled and the U-labelled compounds were combined into two working solutions (one for the unlabelled mycotoxins in acetonitrile:water $(80: 20, v / v)$ and one for the $U$ labelled analogues in acetonitrile). The working solution of the unlabelled mycotoxins had the following concentrations: AFB1, $20 \mathrm{ng} / \mathrm{ml}$; DON, 4,000 ng/ml; FB1, 2,000 ng/ml; FB2, $800 \mathrm{ng} / \mathrm{ml} ; F B 3$, $400 \mathrm{ng} / \mathrm{ml} ; \mathrm{HT}-2,400 \mathrm{ng} / \mathrm{ml}$; OTA, $40 \mathrm{ng} / \mathrm{ml} ; \mathrm{T}-2,400 \mathrm{ng} / \mathrm{ml}$; ZEA, $1000 \mathrm{ng} / \mathrm{ml}$. For the internal calibration method the exact concentration of the labels need to be known. Therefore, the concentrations of the [13C]-labelled working solutions obtained were determined by reverse isotope dilution analysis and established to be: [13C17]-AFB1, $10.78 \mathrm{ng} / \mathrm{ml}$; [13C15]-DON, 1,290 ng/ml; [13C34]-FB1, $462 \mathrm{ng} / \mathrm{ml} ;$ [13C34]-FB2, $270 \mathrm{ng} / \mathrm{ml}$; [13C34]-FB3, $130 \mathrm{ng} / \mathrm{ml}$; [13C22]- HT-2, $250 \mathrm{ng} / \mathrm{ml}$; [13C20]-OTA, $28 \mathrm{ng} / \mathrm{ml}$; [13C24]-T-2, $224 \mathrm{ng} / \mathrm{ml}$ and [13C18]-ZEA, $700 \mathrm{ng} / \mathrm{ml}$. All standard solutions (stock, intermediate and working solutions) were stored in amber glass bottles in a fridge. Prior to usage, the working solutions were brought to room temperature and were mixed thoroughly.

\section{Samples}

Feed samples (soybean meal and wheat straw) and spice samples (nutmeg, paprika, curcuma and ginger) were used to study the feasibility of the compensation of matrix effects through of a 'matrixmarker' substance. The comparison of different calibration strategies was carried out using five different food and feed commodities: maize, compound feed, wheat straw, nutmeg and curcuma. The selection of the matrices was based on the moderate to strong signal suppression associated with these types of matrices. Maize was chosen as the least complex matrix in this work, but its relative high matrix effects have been widely described (Beltran et al., 2009; De Girolamo et al., 2013).

\section{Sample preparation}

Ground and homogenised samples $(2.50 \pm 0.01 \mathrm{~g})$ were weighed into $50-\mathrm{ml}$ polypropylene tubes. Samples were extracted by shaking with $10 \mathrm{ml}$ acetonitrile/water/formic acid (84:16:1) (extraction solution) on a mechanical shaker (SM 30 control, Edmund Buhler, Hechingen, Germany) (170-200 movements/min) for $2 \mathrm{~h}$. Afterwards, the tubes were centrifuged at 3,000 rpm for $5 \mathrm{~min}$ and $200 \mu \mathrm{l}$ of supernatant was two-fold diluted with HPLC-grade wàter directly in a filter vial (Mini-UniPrep, 0.45 $\mu \mathrm{m}$, Whatman, Forham Park, NJ, USA). In case internal standards were added, this was done at this stage (for details see below). The vials were closed with the corresponding filters and mixed by vortex for $3 \mathrm{~s}$. After being stored in the fridge for $30 \mathrm{~min}$ in order to precipitate part of the coextracted matrix, the extracts were filtered by pressing down the filters.

Due to the high absorption capability of straw samples, the volume of extraction liquid was increased to $20 \mathrm{ml}$ for these samples. Besides, the high degree of homogeneity of spice samples permitted to reduce the amount of sample to $(0.50 \pm 0.01 \mathrm{~g})$ and consequently the volume of extraction solution to $2 \mathrm{ml}$. These samples were weighed in $15 \mathrm{ml}$ Falcon tubes and extracted as described above.

\section{LC-MS/MS analysis}

An UPLC ${ }^{\mathrm{TM}}$ system (Acquity, Waters, Etten-Leur, the Netherlands) coupled to a Micromass Quattro Ultima triple quadrupole mass spectrometer was used (Waters). The analytical column was an Ultra aqueous C18 ( $3 \mu \mathrm{m}$ particle size, 2.1.100 mm; Restek, Bellefonte, PA, USA), at a flow rate of 0.4 $\mathrm{ml} / \mathrm{min}$. The column temperature was set at $35^{\circ} \mathrm{C}$ and the injection volume was $5 \mu \mathrm{l}$. The mobile phase was a time programmed gradient using $\mathrm{A}(\mathrm{H} 2 \mathrm{O})$ and $\mathrm{B}(\mathrm{MeOH}: \mathrm{H} 2 \mathrm{O}, 95: 5, \mathrm{v} / \mathrm{v})$. For positive electrospray conditions both mobile phases were modified with ammonium formate $(1 \mathrm{mM})$ and formic acid $(1 \% \mathrm{v} / \mathrm{v})$. Zearalenone in cúrcuma samples was analysed separately in a second run by 
negative ionisation using mobiles phases modified with ammonium acetate $(5 \mathrm{mM})$ and acetic acid $(0.1 \%)$. The percentage of organic modifier (B) was changed linearly as follows in both conditions: 0 min, 0\%; $1 \mathrm{~min}, 0 \%$; $2 \mathrm{~min}, 50 \%$; $3 \mathrm{~min}$ 50\%; $8 \mathrm{~min}, 100 \%$; $10 \mathrm{~min}, 100 \%$; $10.5 \mathrm{~min}, 0 \%$; $15 \mathrm{~min}, 0 \%$.

The mass spectrometer was operated with electrospray ionisation in selected reaction monitoring (SRM) mode (Table 1). Transitions monitored for 13C3-caffeine, carbendazim and chlormequat were $198>140,192.2>160$ and $122.2>58.3$ respectively. Capillary voltages of $2.5 \mathrm{kV}$ (positive ionisation mode) and $3.5 \mathrm{kV}$ (negative ionisation mode) were applied. Nitrogen was used as the nebulizer gas and argon as the collision gas. The desolvation gas temperature was set to $350^{\circ} \mathrm{C}$ and the source temperature to $120^{\circ} \mathrm{C}$. The cone gas and desolvation flow were set at 200 and $550 \mathrm{l} / \mathrm{h}$ respectively. Dwell times of $80 \mathrm{~ms} /$ transition were used. Instrument control, data acquisition and evaluation (integration and quantification) were done with MassLynx software (v. 4.1, Waters).

\section{Continuous measurement of a 'matrix-marker' substance to correct for matrix effects}

The set-up used was based on that described by Stahnke et al. (2009). However, instead of permanent post-column infusion of the matrix-marker substance into the eluent through a T-piece, which requires an additional pump, the monitored substance was introduced by adding it to the mobile phases.

Three different compounds (13C3-caffeine, carbendazim and chlormequat) were selected as candidate matrixmarker substances and added at a level of $2.5 \mathrm{ng} / \mathrm{ml}$ to both organic and aqueous mobile phases. This level was in accordance with the post-column infusion conditions described by Stahnke et al. (2009). Carbendazim was evaluated as candidate to correct for matrix effects because of its successful use in the Stahnke work. Labelled caffeine was selected as an alternative and has the advantage that it will not be present in samples. Chlormequat, a catiònic compound, was also employed since it presented no interaction with the C18 column and eluted completely unretained.

Experiments were performed under positive electrospray conditions presented in Table 1. Sample extracts $(200 \mu \mathrm{l})$ were spiked with $12.5 \mu \mathrm{l}$ of the unlabelled mix solution and adjusted to a final volume of $400 \mu \mathrm{l}$ with water. Standards were prepared in extraction solution:water $(1: 1, \mathrm{v} / \mathrm{v})$ and injected after every 5 samples. 
Table 1. Experimental conditions of the LC-(ESI)-MS/MS for the selected mycotoxins.

\begin{tabular}{|c|c|c|c|c|c|c|}
\hline \multirow[t]{2}{*}{ Compound } & \multirow{2}{*}{$\begin{array}{l}\text { Retention } \\
\text { time (min) }\end{array}$} & \multirow{2}{*}{$\begin{array}{l}\text { Precursor } \\
\text { ion }\end{array}$} & \multirow{2}{*}{$\begin{array}{l}\text { Cone voltage } \\
\text { (V) }\end{array}$} & \multicolumn{3}{|c|}{ Selected reaction monitoring transitions ${ }^{1}$} \\
\hline & & & & native compound & isotopic label & IPD \\
\hline Deoxynivalenol & 2.8 & {$[\mathrm{M}+\mathrm{H}]^{+}$} & 20 & $\begin{array}{l}297.0>249.1(10) \\
297.0>231.1(10)\end{array}$ & $312.0>263.1(10)$ & $\begin{array}{l}297.0>249.1(10) \\
298.0>250.1(10) \\
312.0>263.1(10)\end{array}$ \\
\hline Aflatoxin $B_{1}$ & 5.2 & {$[\mathrm{M}+\mathrm{H}]^{+}$} & 30 & $\begin{array}{l}313.1>285.1(20) \\
313.1>269.1(30)\end{array}$ & $330.1>301.1(20)$ & $\begin{array}{l}313.1>285.1(20) \\
330.1>301.1(20) \\
330.1>300.1(20)\end{array}$ \\
\hline HT-2 toxin & 5.2 & {$\left[\mathrm{M}+\mathrm{NH}_{4}\right]^{+}$} & 20 & $\begin{array}{l}442.2>263.1(10) \\
442.2>215.1(15)\end{array}$ & $464.2>278.1(10)$ & $\begin{array}{l}442.2>263.1(10) \\
443.2>264.1(10) \\
464.2>278.1(10)\end{array}$ \\
\hline Fumonisin $\mathrm{B}_{1}$ & 5.5 & {$[\mathrm{M}+\mathrm{H}]^{+}$} & 30 & $\begin{array}{l}722.2>334.2(40) \\
722.2>352.2(30)\end{array}$ & $756.2>356.2(40)$ & $\begin{array}{l}722.2>334.2(40) \\
723.2>335.2(40) \\
756.2>356.2(40)\end{array}$ \\
\hline$T-2$ toxin & 5.8 & {$\left[\mathrm{M}+\mathrm{NH}_{4}\right]^{+}$} & 20 & $\begin{array}{l}484.2>185.1(20) \\
484.2>305.1(10)\end{array}$ & $508.2>198.1(20)$ & $\begin{array}{l}484.2>185.1(20) \\
485.2>186.1(20) \\
508.2>198.1(20)\end{array}$ \\
\hline Fumonisin $\mathrm{B}_{3}$ & 5.9 & {$[\mathrm{M}+\mathrm{H}]^{+}$} & 30 & $\begin{array}{l}706.2>336.2(40) \\
706.2>318.2(40)\end{array}$ & $740.2>358.2(40)$ & $\begin{array}{l}706.2>336.2(40) \\
707.2>337.2(40) \\
740.2>358.2(40)\end{array}$ \\
\hline Fumonisin $\mathrm{B}_{2}$ & 6.1 & {$[\mathrm{M}+\mathrm{H}]^{+}$} & 30 & $\begin{array}{l}706.2>336.2(40) \\
706.2>318.2(40)\end{array}$ & $740.2>358.2(40)$ & $\begin{array}{l}706.2>336.2(40) \\
707.2>337.2(40) \\
740.2>358.2(40)\end{array}$ \\
\hline Ochratoxin A & 6.6 & {$[\mathrm{M}+\mathrm{H}]^{+}$} & 30 & $\begin{array}{l}404.2>239.1(30) \\
404.2>221.1(35)\end{array}$ & $424.2>250.1(30)$ & $\begin{array}{l}404.2>239.1(30) \\
406.2>241.1(30) \\
424.2>250.1(30)\end{array}$ \\
\hline Zearalenone (ZEA+) & 6.6 & {$[\mathrm{M}+\mathrm{H}]^{+}$} & 20 & $\begin{array}{l}319.3>283.0(10) \\
319.3>185.1(30)\end{array}$ & $337.3>301(10)$ & $\begin{array}{l}319.3>283(10) \\
337.3>301(10) \\
336.3>300(10)\end{array}$ \\
\hline Zearalenone $^{2}$ (ZEA-) & 6.8 & {$[\mathrm{M}-\mathrm{H}]$} & 20 & $\begin{array}{l}317.1>175.1(25) \\
317.1>273.1(20)\end{array}$ & $335.1>185.1(25)$ & $\begin{array}{l}317.1>175.1(25) \\
335.1>185.1(25) \\
334.1>184.1(25)\end{array}$ \\
\hline
\end{tabular}

The matrix effect (ME) profile at each retention time was constructed by calculating the ratio, at each point of the chromatogram, between the signal intensity (SI) obtained with the sample extract and that of the reference solvent (reagent blank) with the following expression (Equation 1):

$$
\mathrm{ME}(\%)=(((\mathrm{SI} \text { (sample extract) } / \mathrm{SI}(\text { reference solvent })) \times 100)-100
$$

Once the matrix effect profile is calculated, recoveries corrected for matrix effects can be obtained using the vàlues around the retention time for each compound (Stahnke et al., 2009).

\section{Comparison of quantification approaches}


For comparison of different quantification approaches nine mycotoxins were spiked to five food and feed matrices at levels in the range of legislative or recommended màximum levels. For maize, compound feed and straw $2.5 \mathrm{~g}$ were fortified with $625 \mu \mathrm{l}$ of the working solution of unlabelled mycotoxins. For nutmeg and curcuma $0.5 \mathrm{~g}$ were spiked with $125 \mu \mathrm{l}$ of the same solution. The concentration in fortified samples was established as level 0 (LO), which corresponded to following concentration of mycotoxins in samples: AFB1, $0.005 \mu \mathrm{g} / \mathrm{g}$; DON, $1 \mu \mathrm{g} / \mathrm{g}$; FB1, $0.5 \mu \mathrm{g} / \mathrm{g}$; FB2, $0.2 \mu \mathrm{g} / \mathrm{g}$; FB3, $0.1 \mu \mathrm{g} / \mathrm{g}$; HT-2, $0.1 \mu \mathrm{g} / \mathrm{g}$; OTA, $0.01 \mu \mathrm{g} / \mathrm{g}$; T-2, $0.1 \mu \mathrm{g} / \mathrm{g}$; ZEA, $0.25 \mu \mathrm{g} / \mathrm{g}$. Samples were equilibrated for $30 \mathrm{~min}$ before the extraction.

When measurements involved the use of the labelled mycotoxins, one aliquot of $200 \mu \mathrm{l}$ of the initial extract was spiked with $20 \mu \mathrm{l}$ of the labelled mixture and diluted with $180 \mu \mathrm{l}$ of deionised water. The fortified samples were quantitatively analysed on three different days. From the data obtained the average recovery and the precision (expressed as relative standard deviation (RSD) in \%) were determined using five different calibration approaches:

Multi-level external calibration using isotopically labelled internal standards

For this $20 \mu \mathrm{l}$ of the labelled mycotoxin mix was added to $200 \mu \mathrm{l}$ of the sample extract and deionised water was added to obtain a final volume of $400 \mu$ l. Calibration standards in extraction solvent:water (1:1) were prepared containing the mycotoxins at concentrations corresponding to $0,0.5,1,2.5$ and 10 times the concentration corresponding to LO in sample and the IL-IS at the same level as in the final sample extracts. The response of the mycotoxin was normalised to that of the corresponding labelled internal standard. The concentration of the mycotoxins were determined using the equation of the calibration curve obtained using the normalised responses. For comparison, the calculations were also done without using the labels (i.e. without correction for matrix effects).

\section{Multi-level standard addition}

Four aliquots from the same sample extract were used to perform the recovery calculations based on Standard additions. These were prepared by adding successively the mixture of the natural compounds to $200 \mu \mathrm{l}$ of extract of the fortified samples to obtain a final level of 1.5 times (level 1 , L1), 3 times (level 2, L2) and 4.5 times (level 3, L3) the level added to the spiked samples (LO). Deionised water was added to obtain a final volume of $400 \mu$ l. The concentration of mycotoxin was determined from the intercept of the calibration curve with the $\mathrm{X}$-axis.

\section{Single-level standard addition}

For this quantification method the data from the multilevel standard addition method were used. The concentration was calculated by:

$$
\text { Concentration }=\frac{\text { Area } L x}{\text { Area }(\mathrm{Lx}-\mathrm{L} 0)} \times \text { Concentration } \mathrm{Lx}
$$

with Lx being the standard addition level, and LO the level in the fortified sample. This single-point Standard addition calibration was performed for each of the three levels individually.

\section{One-point isotopic internal calibration}

One IL-IS for each compound, and a simple crossmultiplication is used to determine the concentration in the extracts for each sample injection. No calibration curve is used. For this $20 \mu \mathrm{l}$ of the labelled mycotoxin mix was added to $200 \mu \mathrm{l}$ of the extract (blank or fortified) and deionised water was added to obtain a final volume of $400 \mu \mathrm{l}$. The concentration of the IL-IS in the extract corresponded to that of the fortification levels in the samples. The concentration of the mycotoxin was calculated by:

Concentration $=\frac{\text { Area } \mathrm{Mx}}{\text { Area Mxl }} \times$ Concentration Mxl

with $\mathrm{Mx}=$ mycotoxin, $\mathrm{Mxl}=$ labelled mycotoxin 


\section{Isotope pattern deconvolution}

IPD as used in this work is an alternative form of OPIC. IPD is a mathematical tool employed in isotope dilution MS to obtain the concentration of each compound in the sample by multiple linear regressions without the need to build any calibration curve. This approach assumes that, after spiking the sample with the labelled analogue, the final isotòpic composition observed in the mixture is a combination of the analyte and the isotopically enriched spike. Afterwards, solving the system of equations formed by the abundances, the ratio of molar fractions is obtained and consequently the concentration of analyte in sample. This approach needs the measurement of the isotopic composition of both natural and labelled compounds by mass spectrometry (Gonzalez-Antuna et al., 2010). Taking into account the limited number of transitions that can be simultaneously measured by LC-MS/MS, the most sensitive transitions should be known in advance. It is possible to calculate the most abundant isotopomer combination for a selected transition by the use of the software Isopatrn (Ramaley and Cubero Herrera, 2008), but the molecular formula of both precursor and product ions must be available. The proposed molecular formula has been obtained by either previous works (Bartok et al., 2006; Varga et al., 2012) or deducted by using Xcalibur software (Thermo Fisher Scientific, San Jose, CA, USA) and was double checked with in-house exact mass databases (Supplementary Table S1). The selected transitions for IPD calculations are included in Table 1. For IPD calculations 3 transitions are used: the most abundant for natural and labelled compounds and a third one, sensitive enough and free of interferences. A minimum number of three transitions is necessary in order to be able solve the system of equations formed by the abundances by multiple linear regression with a least square fitting.

$$
\left[\begin{array}{l}
A_{m i x}^{S R M 1} \\
A_{m i x}^{S R M 2} \\
A_{m i x}^{S R M 3}
\end{array}\right]=\left[\begin{array}{ll}
A_{\text {nat }}^{S R M 1} & A_{\text {lab }}^{S R M 1} \\
A_{\text {nat }}^{S R M 2} & A_{\text {lab }}^{S R 2} \\
A_{\text {nat }}^{S R M 3} & A_{\text {lab }}^{S R M 3}
\end{array}\right]\left[\begin{array}{c}
X_{\text {nat }} \\
X_{\text {lab }}
\end{array}\right]+\left[\begin{array}{l}
e^{S R M 1} \\
e^{S R M 2} \\
e^{S R M 3}
\end{array}\right]
$$

In this system of equations $A_{m i x}^{S R M i}$ values corresponds to the measured abundance of the compound in the mixture for the SRM transition of nominal masses i>j, $A_{\text {nat }}^{S R M i}$ and $A_{L a b}^{S R M i}$ experimentally measured abundances for the pure natural and labelled mycotoxins and ei>j is the error vector of the multiple linear regression. By solving the previous system of equations, molar fractions for natural and labelled compounds (Xnat and Xlab) in the mix are obtained, and the amount (mols) of natural abundance mycotoxin in the sample, Nnat, is then calculated using Equation (5) where the amount (mols) of each labelled mycotoxins added, Nlab, must be known.

$$
\mathrm{N}_{\text {nat }}=\mathrm{N}_{\mathrm{lab}}\left(\mathrm{X}_{\mathrm{nat}} / \mathrm{X}_{\mathrm{lab}}\right)
$$

It should be noted the probability of errors caused by the contribution of fragmentation before Q1. For example, the transition $319 \rightarrow 283$, which starts at the $[\mathrm{M}+\mathrm{H}]$ of native ZEA may be theoretically influenced by the fragment ion [M+H-H2O]+ of 13C18-ZEA. However, our measurements will be biased only if [ $\mathrm{M}+\mathrm{H}-\mathrm{H} 2 \mathrm{O}]$ of $13 \mathrm{C} 18-\mathrm{ZEA}$ has also a main fragment in $\mathrm{Q} 2$ of $\mathrm{m} / \mathrm{z} 283$ which it is not the case.

The samples used for this study turned out to be contaminated with certain mycotoxins (Supplementary Table S2). In these cases, the amount present in the non fortified samples was subtracted from that of the fortified samples in all quantification approaches. Since no blank samples were available for the majority of the matrices, an unspiked sample was prepared for each matrix. A volume of $200 \mu \mathrm{l}$ of the final extract was fortified with $20 \mu \mathrm{l}$ of the labelled mixture and $180 \mu \mathrm{l}$ of water in order to be able to subtract the amount of each mycotoxin found in the samples by all the quantification methodologies. 


\section{Determination of matrix effects by post-extraction addition}

Matrix effects were calculated by comparison of the response of a mycotoxin in sample extract with the response of the same concentration in a solvent standard. This was done at the L2 level.

Endogenous concentrations of mycotoxins in the samples were taken into account (subtracted) in the calculations.

$$
\mathrm{ME}=(\text { Area }(\text { matrix }) / \text { Area (solvent })) \times 100-100
$$

\section{Results and discussion}

\section{Assessment of the feasibility of compensation of matrix effects through the signal of a continuously monitored substance}

The work of Stahnke et al. (2009) establishes that the ion suppression or enhancement for a monitored substance can be extrapolated to other analytes if they elute at the same retention time, and therefore can be used to correct for matrix effects. To study the applicability of this approach, three 'matrix-marker' substances (13C-caffeine, carbendazim and chlormequat) were tested. In this work, in order not to complicate the instrumental configuration, the substances were added to the mobile phase rather than by post-column infusion as done by Stahnke et al. At least one injection for stabilisation of the system when starting a new sequence was performed. By doing so, no indications for concentration fluctuations of the marker substance due to absorption in the LC-pump or valve were observed. First the signal intensities of the three substances during the entire chromatographic run were measured without matrix (injection of reagent blank; Figure 1A). 

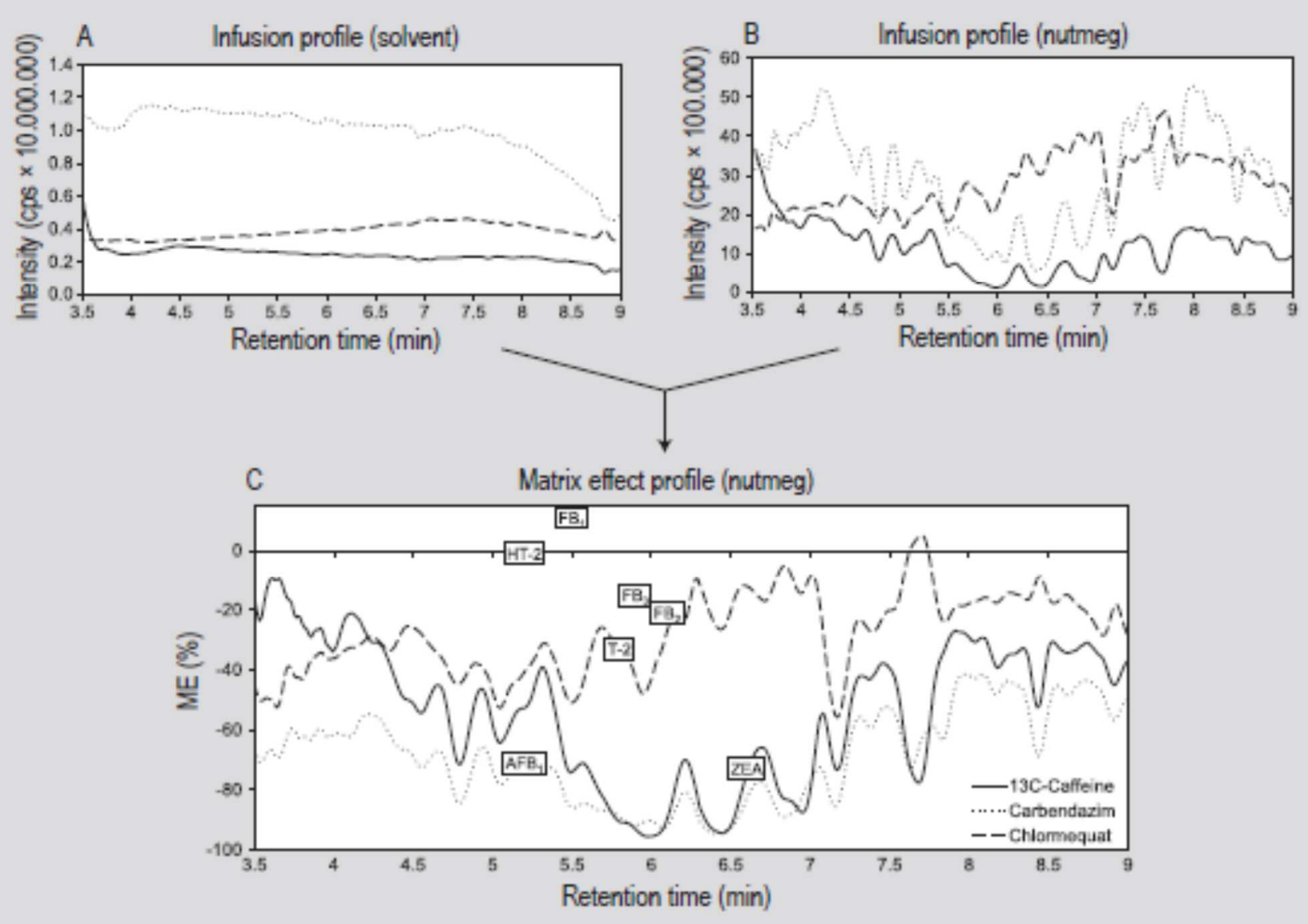

Figure 1. (A) Signal profile for ${ }^{13} \mathrm{C}$-caffeine, carbendazim and chlormequat after the injection of the reference solvent and (B) after the injection of a nutmeg extract in a second run. (C) Matrix effect (ME) profile calculated as the ratio of the two infusion profiles together with the matrix effects obtained by post-extraction addition at each retention time for each mycotoxin. Boxes with the mycotoxin code: position on the $\mathrm{Y}$-axis indicate the actual suppression/enhancement for that mycotoxin, the lines on either side of the box indicate its peak width. $\mathrm{AFB}_{1}=$ aflatoxin $\mathrm{B}_{1}, \mathrm{FB}_{1}, \mathrm{FB}_{2}, \mathrm{FB}_{3}=$ fumonisin $\mathrm{B}_{1}, \mathrm{~B}_{2}$ and $\mathrm{B}_{3} ; \mathrm{T}-2, \mathrm{HT}-2=\mathrm{T}-2$ and HT-2 toxin; ZEA = zearalenone.

This basically shows the effect of the mobile phase gradient on the response of each of the three substances. Next, the signal intensities were measured after injection of extracts of diferent matrices known to cause moderate to strong matrix effects (a soy by-product used as feed ingredient, wheat straw, nutmeg (shown in Figure 1B), paprika, curcuma and ginger). Then, the matrix effect profiles were constructed based on the ratio of the signals obtained after injection of sample extract and reagent blank versus retention time (Figure $1 \mathrm{C}$ for nutmeg, Figure 2 for curcuma and wheat straw, more examples in the Supplementary Figure S1). One limitation of the set-up to add the substances to the mobile phase (instead of post-column infusion) was that due to the interaction of carbendazim and 13C-caffeine with the stationary phase (retention time 2.8 and $3.3 \mathrm{~min}$, respectively), these compounds were initially accumulated in the column until their constant elution. For this reason, the usable matrix-effect profiles ranged from 3.5 to $9 \mathrm{~min}$. 

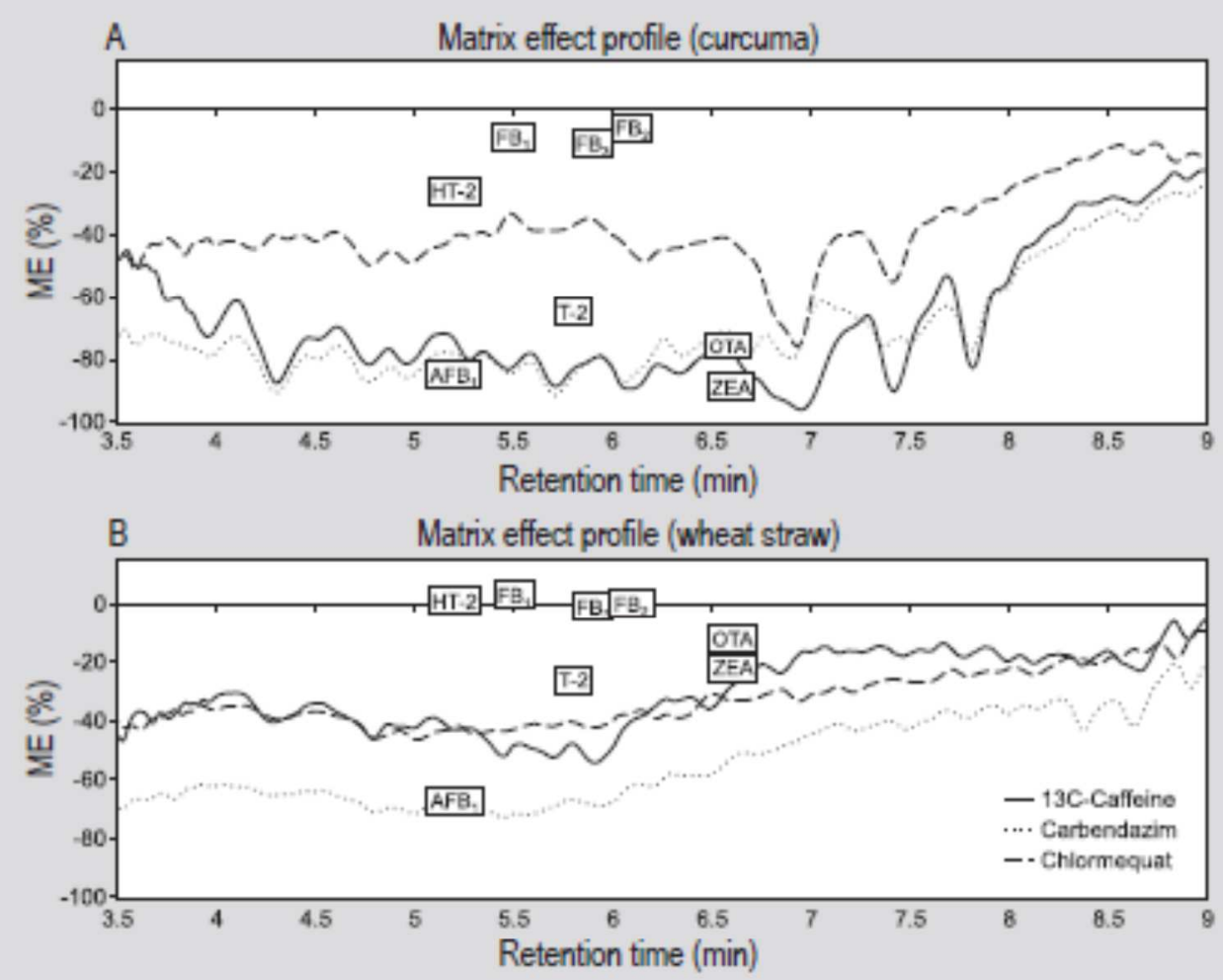

Figure 2. Matrix effect (ME) profile for (A) curcuma and for (B) wheat straw. The matrix effects obtained by post-extraction addition at each retention time for each mycotoxin are also included. Boxes with the mycotoxin code: position on the $\mathrm{Y}$-axis indicate the actual suppression/enhancement for that mycotoxin, the lines on either side of the box indicate its peak width. $A F B_{1}=$ aflatoxin $B_{1}$; $\mathrm{FB}_{1}, \mathrm{FB}_{2}, \mathrm{FB}_{3}=$ fumonisin $\mathrm{B}_{1}, \mathrm{~B}_{2}$ and $\mathrm{B}_{3} ; \mathrm{T}-2, \mathrm{HT}-2=\mathrm{T}-2$ and $\mathrm{HT}-2$ toxin; OTA = ochratoxin $\mathrm{A}$; ZEA = zearalenone.

The graphs very nicely show that the matrix effects, mostly suppression, varies widely for different matrices and at different retention times. The objective of these graphs was to obtain the matrix effect values at the retention time of each of the mycotoxins and then use these values to correct for the matrix effect. The first observation that can be made from the matrix-effect profiles for the three marker substances is that they overlap to a certain extent, but not consistently, and that remarkable differences do occur. For example, in Figure $2 \mathrm{~A}$ in the elution range of the mycotoxins (up to approx. $7 \mathrm{~min}$ ) the magnitude of suppression for carbendazim and 13C-caffeine is similarly strong, but much less suppression occurs for chlormequat. The different values obtained between chlormequat and the other two compounds can be explained, at first, by the different psychochemical properties since chlormequat is a highly ionised compound. However, for wheat straw, 13C-caffeine and chlormequat are overlapping quite well while carbendazim is clearly more suppressed. In certain matrices and at certain retention times, very large variations in matrix effects between the three marker substances can be seen, for example for ginger (Figure S1) at $5.0 \mathrm{~min}$, the suppression of 13C-caffeine and chlormequat is similar and carbendazim is deviating, while at $5.5 \mathrm{~min} 13 \mathrm{C}$-caffeine and carbendazim are similar and chlormequat is deviating.

These differences cannot be readily explained by the physico-chemical properties of the monitored compounds. In Figure $1 \mathrm{C}$ and 2 the actual matrix effects for individual mycotoxins, determined by comparison of the response in matrix versus the response in solvent standards, are also included. From this is it clear that similar observations can be made for the other mycotoxins and matrices (Figure 1C, Figure 2). Also for mycotoxins that co-elute (e.g. aflatoxin B1 and HT-2 toxin) substantial differences occur (see also Table 2 and 3, and Supplementary Tables S2-S4). The results demonstrate that the correction of the matrix effect by monitoring a 'matrix-marker' substances is an unsuitable approach for the correction of matrix effects for the tested conditions. Although the approach seems 
appropriate for the pesticides and matrices from the work by Stahnke et al. (2009), it was not suited for the mycotoxins and matrices studied in the present work. The reasons for this were not fully clear, but might be related to the type of matrix, the higher degree of suppression (especially spices) and/or the instrumental conditions used. However, the method provides a qualitative assessment of the matrix effect and enables the researcher to evaluate the alteration of the analyte response at each retention time.

\section{Comparison of different calibration approaches}

In the comparison nine mycotoxins (AFB1, DON, FB1, FB2, FB3, HT-2, OTA, T-2 and ZEA) were selected based on the availability of the isotopically labelled analogues of the sought compounds and, except for FB3, their inclusion in the European Union food legislation. Maize, compound feed, straw, nutmeg and curcuma were selected due to their known moderate to high signal suppression. The average matrix effects and its variability (standard deviation) for the different mycotoxin/matrix combinations as measured on three different days are included in Table 2 (maize), Table 3 (nutmeg), Supplementary Table S3 (compound feed), Supplementary Table S4 (wheat straw), and Supplementary Table $\mathbf{S 5}$ (curcuma). Matrix effects were calculated according to Equation 6 . To this end, the ratio between the areas of the standard prepared in solvent and in sample extract were compared. In view of these results, the compounds affected by a higher suppression were AFB1 and DON for all the matrices. Moreover, the signal of ZEA was also affected by the matrix of both studied spices, while T-2 and OTA were mostly affected by the cúrcuma matrix. In general, matrix effects for all analytes were more pronounced in spice samples, in particular curcuma, than in maize, compound feed or straw. Malachova et al. (2014) have previously reported this in green pepper.

For the evaluation of trueness, samples were spiked with working solution (unlabelled mycotoxins) at one level before extraction. The concentration levels were selected according to typical legislative or recommended limits and were established as level 0 (LO) (see materials and methods for specific values). Recoveries of the selected mycotoxins were first calculated by the standard addition method (addition to the extract). As the quantification is carried out in the same matrix, the standard addition method compensates for any matrix effect and the extraction recovery can be assessed. The standard addition calculations were performed by adding the working solution of natural mycotoxins to different aliquots of the same extract to obtain a final level of 1.5 times (level 1, L1), 3 times (level $2, \mathrm{L2}$ ) and 4.5 times (level 3, L3) the level spiked to sample (LO). This permitted to obtain a four-point calibration graph built with the spiked sample and the three post-extraction levels. Moreover, the recoveries were also calculated based on single Standard addition using each of the three levels.

Alternatively, the isotope-labelled mycotoxins, added to an extract aliquot of $\mathrm{LO}$, were used as internal standard for calculating the recoveries by a five-point calibration curve in solvent, and by two single-point calibration approaches: OPIC and IPD (see materials and methods for details). The main difference between the single-point calculations is the use of three isotopomer abundances in a multiple linear regression (IPD) instead of a cross-multiplication (OPIC) to determine the concentration in the sample.

Satisfactory linearity by standard addition and internal standard calibration curve with correlation coeficients above 0.995 in all sample matrices was obtained, excepte for OTA in straw and curcuma for the standard addition method. For this reason this analyte was excluded in the comparison by standard additions (either, multiple or single addition) in straw and curcuma. Besides, OTA was affected by a co-eluting isobaric interference in nutmeg samples. Finally, due to the lower sensitivity in cúrcuma samples, no second transition, needed for IPD calculations, was observed and consequently the recovery calculations could not be performed. All the difficulties regarding OTA calculations were related to the low levels and lower sensitivity (partly due to the high suppression) of this compound.

Trueness and precision 
Regarding the three-day recovery study, the trueness (recovery) and precision are shown in Tables 2 and 3 and Supplementary Tables S3 to S5 for maize, nutmeg, compound feed, straw and curcuma, respectively. Recovery and precision are assessed according to EU Regulation 519/2014 (EC, 2014). The recovery requirements in this regulation vary for the different mycotoxins and concentrations (for the fortification levels in this work: $50-120 \%$ for AFB1, $60-130 \%$ for T-2/H-T2-toxins, $60-120 \%$ for fumonisins, $70-120 \%$ for DON and ZEA, and $70-110 \%$ for OTA). For precision, the repeatability (RSDr) requirement from EU Regulation 519/2014 were used, even though the data were generated under within-lab reproducibility conditions. The RSDr requirements vary for the different mycotoxins and range from 20-30\%. For the standard addition method, recoveries and RSDr met the requirements in all cases with the following exceptions: OTA in maize (Table 2), and DON, AFB1, and ZEA in Straw (Supplementary Table S4). Quantification methods based on a single-level standard addition can provide appropriate results except when the addition level is too close to the level present in the sample. Here that was the case for level L1 resulting in a small response difference with LO. Minor variations in response of either LO or L1 will lead to wide variations in the analysis result. This explains the high RSD values and the recoveries outside the EU Regulation 519/2014 acceptance criteria. As long as the addition is 3 or 4.5 times the level in the sample, similar results were obtained as compared to multi-level standard addition. Considering that only two injections instead of four for each quantitation were needed for the single-addition method, this approach considerably reduced the total analysis time and could be the best option when no IL-IS is available.

Table 2. Matrix effect and recoveries in percentage of mycotoxins in maize using different calibration approaches. ${ }^{1,2}$

\begin{tabular}{|c|c|c|c|c|c|c|c|c|c|}
\hline \multirow[t]{4}{*}{ Compound } & \multirow{4}{*}{$\begin{array}{l}\text { Matrix } \\
\text { effect } \pm \\
\text { SD }\end{array}$} & \multicolumn{8}{|c|}{ Recoveries and repeatability relative standard deviation $\left(\mathrm{RSD}_{r}\right.$, in brackets), $\mathrm{n}=3$, three different days } \\
\hline & & \multicolumn{3}{|c|}{ Multi-level calibration } & \multicolumn{5}{|c|}{ Single-level calibration } \\
\hline & & \multirow{2}{*}{$\begin{array}{l}\text { Solvent } \\
\text { STD w/o } \\
\text { IL-IS }\end{array}$} & \multirow{2}{*}{$\begin{array}{l}\text { Solvent } \\
\text { STD with } \\
\text { IL-IS }\end{array}$} & \multirow{2}{*}{$\begin{array}{l}\text { Standard addition } \\
\text { L1-L3 }\end{array}$} & \multicolumn{3}{|c|}{ Standard addition } & \multicolumn{2}{|c|}{ Internal calibration } \\
\hline & & & & & L1 & L2 & $\mathbf{L 3}$ & OPIC & IPD \\
\hline Deoxynivalenol & $-21 \pm 16$ & $67(26)$ & $91(14)$ & $93(3)$ & $78(11)$ & $87(7)$ & $89(6)$ & $102(14)$ & $95(14)$ \\
\hline Aflatoxin $B_{1}$ & $-41 \pm 14$ & $59(19)$ & $110(8)$ & $108(18)$ & $90(40)$ & $102(24)$ & $103(20)$ & 109 (11) & $117(9)$ \\
\hline HT-2 toxin & $21 \pm 13$ & 99 (11) & $108(20)$ & 95 (10) & $100(25)$ & $90(22)$ & $94(14)$ & $103(25)$ & $114(25)$ \\
\hline Fumonisin $\mathrm{B}_{1}$ & $2 \pm 28$ & $74(35)$ & $99(16)$ & $80(12)$ & $60(13)$ & $73(10)$ & 75 (10) & $121(10)$ & $111(10)$ \\
\hline $\mathrm{T}-2$ toxin & $3 \pm 13$ & $105(9)$ & $115(11)$ & $100(3)$ & $82(13)$ & $100(6)$ & $98(5)$ & $121(12)$ & $108(12)$ \\
\hline Fumonisin $B_{3}$ & $4 \pm 25$ & $98(26)$ & $105(21)$ & $100(17)$ & $78(3)$ & 93 (12) & $96(20)$ & $115(29)$ & $101(29)$ \\
\hline Fumonisin $\mathrm{B}_{2}$ & $9 \pm 22$ & $104(27)$ & $110(21)$ & $99(6)$ & $91(18)$ & $95(6)$ & $97(7)$ & $142(17)$ & $136(16)$ \\
\hline Ochratoxin $A$ & $-9 \pm 18$ & $95(26)$ & $113(10)$ & $92(29)$ & $145(66)$ & $90(15)$ & 94 (19) & $127(18)$ & 131 (19) \\
\hline Zearalenone & $3 \pm 7$ & $104(18)$ & $106(13)$ & $103(6)$ & $124(44)$ & $105(16)$ & 104 (11) & $107(13)$ & 109 (13) \\
\hline
\end{tabular}

Quantification using the calibration curve with the internal standard method also provided accurate results together with proper precision values. When available, quantification using IL-IS has been demonstrated as a proper alternative to correct matrix effect.

The results obtained using single point calibration (OPIC and IPD), with several recovery values outside the requirements, were worse than expected, although precision was comparable with those based on a calibration curve. One explanation for the observed bias might be deviations in the true 
concentrations of labelled mycotoxins. OPIC and IPD should, at first, show some advantages.

Standard (labelled compounds) are added to the sample and relative signal (OPIC) or isotopomer abundances (IPD) are directly measured in matrix. Thus, the matrix effect should be corrected as in the standard addition method and in external calibration using the isotope labels to normalise the response. On the other hand no calibration curve is used and quantitation can be performed by only one injection per sample, making it a fast method (Castillo et al., 2013; Gonzalez-Antuna et al., 2013; Peters and Maurer, 2007). However, incorrect high recoveries were obtained for fumonisins, OTA and T-2 in some of the matrices studied, especially for the OPIC method as can be seen in maize (Table 2), nutmeg (Table 3), compound feed (Supplementary Table S3) and straw (Supplementary Table S4). In any case, with the exception of FB2 in maize, FB2 and FB3 in nutmeg and the three studied mycotoxins in straw, recoveries (and precision) calculated by IPD and OPIC are comparable to the calibration curve methods but with a considerable reduction of the total analysis time.

The comparison of the different calibration approaches shows that there are various ways to achieve acceptable results. It should be noted that some of the recovery and precision data were affected by the subtraction of the endogenous amount of mycotoxins in the samples (Supplementary Table S2), as no blank samples were available, and to the fact that the additions (Standard additions or internal standard) were performed to the final extract rather than to the sample itself. Thus, the sample treatment process effect on precision was not corrected. However, post-extraction addition is a less expensive method, since lower quantities can be added, especially for the expensive labelled mycotoxins.

Table 3. Matrix effect and recoveries in percentage of mycotoxins in nutmeg using different calibration approaches. ${ }^{1.2}$

\begin{tabular}{|c|c|c|c|c|c|c|c|c|c|}
\hline \multirow[t]{4}{*}{ Compound } & \multirow{4}{*}{$\begin{array}{l}\text { Matrix } \\
\text { effect } \pm \\
\text { SD }\end{array}$} & \multicolumn{8}{|c|}{ Recoveries and repeatability relative standard deviation ( RSD $_{r}$, in brackets), $n=3$, three different days } \\
\hline & & \multicolumn{3}{|c|}{ Multi-level calibration } & \multicolumn{5}{|c|}{ Single-level calibration } \\
\hline & & \multirow{2}{*}{$\begin{array}{l}\text { Solvent } \\
\text { STD w/o } \\
\text { IL-IS }\end{array}$} & \multirow{2}{*}{$\begin{array}{l}\text { Solvent } \\
\text { STD with } \\
\text { IL-IS }\end{array}$} & \multirow{2}{*}{$\begin{array}{l}\text { Standard addition } \\
\text { L1-L3 }\end{array}$} & \multicolumn{3}{|c|}{ Standard addition } & \multicolumn{2}{|c|}{ Internal calibration } \\
\hline & & & & & $\mathbf{L} 1$ & L2 & L3 & OPIC & IPD \\
\hline Deoxynivalenol & $-54 \pm 5$ & $41(2)$ & $92(9)$ & $92(17)$ & $103(28)$ & $92(9)$ & $95(15)$ & $104(12)$ & $97(12)$ \\
\hline Aflatoxin $B_{1}$ & $-71 \pm 5$ & $28(20)$ & $95(13)$ & $102(14)$ & $115(46)$ & $99(29)$ & $103(20)$ & $94(16)$ & $100(17)$ \\
\hline HT-2 toxin & $-1 \pm 13$ & $85(9)$ & $103(6)$ & $94(3)$ & $128(32)$ & 95 (18) & $102(5)$ & $98(10)$ & $107(9)$ \\
\hline Fumonisin $B_{1}$ & $11 \pm 5$ & $97(10)$ & $90(9)$ & $95(25)$ & $115(30)$ & 89 (12) & $102(29)$ & $108(20)$ & $99(20)$ \\
\hline $\mathrm{T}-2$ toxin & $-33 \pm 10$ & 65 (16) & $96(10)$ & $100(25)$ & $142(37)$ & $101(10)$ & $112(32)$ & $111(5)$ & $99(5)$ \\
\hline Fumonisin $B_{3}$ & $-15 \pm 9$ & $90(9)$ & $105(13)$ & $113(25)$ & $108(23)$ & 105 (12) & $118(30)$ & $125(10)$ & $111(10)$ \\
\hline Fumonisin $\mathrm{B}_{2}$ & $-21 \pm 8$ & $72(1)$ & $104(7)$ & $90(23)$ & $94(13)$ & $92(12)$ & $93(21)$ & $125(9)$ & $120(9)$ \\
\hline Ochratoxin $A^{3}$ & - & - & - & - & - & - & - & - & - \\
\hline Zearalenone & $-73 \pm 4$ & $28(10)$ & $112(11)$ & $100(4)$ & $175(29)$ & $112(17)$ & $110(4)$ & $112(12)$ & 114 (13) \\
\hline
\end{tabular}

\section{Conclusions}

An exhaustive study on the extent of matrix effects and applicability of four mathematical methodologies for their correction in LC-ESI-MS/MS mycotoxins analysis in challenging matrices has been reported. The correction of the matrix effect by monitoring the signal of a continuously added 
substance was studied but without satisfactory results. The assumption that the matrix effect for a monitored compound can be extrapolated to other analytes if it occurs at the same retention time is not applicable for the mycotoxins and matrices in the present study. Otherwise, this approach permitted a qualitative evaluation of the signal suppression and enhancement phenomena at each retention time.

The evaluation of absolute matrix effects exhibited by the electrospray source in the LC-MS/MS system showed that the signal was particularly supressed in spice samples. Generally, DON and AFB1 were the analytes affected by the highest suppression. The majority of recovery and RSD values were between $70-120 \%$ and below $20 \%$, respectively, for the standard addition method (both for multiple or single addition at adequate concentration levels) and when using a calibration curve with an IL-IS. Thus, those methodologies all compensate sufficiently for the matrix effect, and trueness and precision meet the EU Regulation 519/2014 acceptance criteria. When suitable internal standards are not available, single-level standard addition methods can be the choice as it reduces considerably the total analysis time.

This study has also demonstrated that single-point calibration approaches (OPIC and IPD) provide similar results, in terms of recovery and precision, to the values obtained with the whole calibration curve. Nevertheless, recoveries for single-point calculations with isotope labelled internal standards occasionally led to unacceptable high recoveries. Further verification of the trueness of the concentration of the labelled mycotoxin solutions is needed to resolve this given that those methods are the fastest (only one injection per sample is needed) and can correctly compensate the matrix effect.

\section{Acknowledgements}

The Dutch Ministry of Economic Affairs is acknowledged for financially supporting this work. The authors acknowledge the financial support from Generalitat Valenciana (Research group of excellence Prometeo 2009/054 and Collaborative Research on Environment and Food Safety ISIC/2012/016). N. Fabregat-Cabello also acknowledges the Generalitat Valenciana for her Ph.D. research grant under the Program VALi+D.

\section{References}

Bartok, T., Szecsi, A., Szekeres, A., Mesterhazy, A. and Bartok, M., 2006. Detection of new fumonisin mycotoxins and fumonisinlike compounds by reversed-phase high-performance líquid chromatography/electrospray ionization ion trap mass spectrometry. Rapid Communications in Mass Spectrometry 20: 2447-2462.

Beltran, E., Ibanez, M., Portoles, T., Ripolles, C., Sancho, J.V., Yusa, V., Silvia, M. and Hernandez, F., 2013. Development of sensitive and rapid analytical methodology for food analysis of 18 mycotoxins included in a total diet study. Analytica Chimica Acta 783: 39-48.

Beltran, E., Ibanez, M., Sancho, J.V. and Hernandez, F., 2009. Determination of mycotoxins in different food commodities by ultrahigh pressure liquid chromatography coupled to triple quadrupole mass spectrometry. Rapid Communications in Mass Spectrometry 23: 1801-1809. Bennett, J.W. and Klich, M.,2003. Mycotoxins. Clinical Microbiology Reviews 16: 497-516. Berthiller, F., Burdaspal, P.A., Crews, C., Iha, M.H., Krska, R., Lattanzio, V.M.T., MacDonald, S., Malone, R.J., Maragos, C., Solfrizzo, M., Stroka, J. and Whitaker, T.B., 2014. Developments in mycotoxin analysis: an update for 2012-2013. World Mycotoxin Journal 7: 3-33.

Castillo, A., Gracia-Lor, E., Roig-Navarro, A.F., Sancho, J.V., Rodriguez- Gonzalez, P. and Garcia Alonso, J.I., 2013. Isotope patern deconvolution-tandem mass spectrometry for the determination and confirmation of diclofenac in wastewaters. Analytica Chimica Acta 765: 77-85.

De Girolamo, A., Solfrizzo, M., Lattanzio, V.M.T., Stroka, J., Alldrick, A., Van Egmond, H.P. and Visconti, A., 2013. Critical evaluation of LC-MS-based methods for simultaneous determination of 
deoxynivalenol, ochratoxin A, zearalenone, aflatoxins, fumonisins and T-2/HT-2 toxins in maize. World Mycotoxin Journal 6: 317-334.

European Commission (EC), 2002, Commission Directive No. 2002/32/ EC of 7 May 2002 of the European Parliament and of the Council on undesirable substances in animal feed, Official Journal of the European Communities L 140: 10-21.

European Commission (EC), 2006a. Commission Recommendation 2006/576/EC of 17 August 2006 on the presence of deoxynivalenol, zearalenone, ochratoxin A, T-2 and HT-2 and fumonisins in products intended for animal feeding. Official Journal of the European Union L 229: 7-9.

European Commission (EC), 2006b. Commission Regulation (EC) No. 1881/2006 of 19 December 2006 setting maximum levels for certain contaminants in foodstuffs. Official Journal of the European Union L 364: 5-24.

European Commission (EC), 2013. Commission Recommendation 2013/165/EU of 27 March 2013 on the presence of T-2 and HT-2 toxin in cereals and cereal products. Official Journal of the European Union L 91: 12-15.

European Commission (EC), 2014, Commission Regulation (EU) No 519/2014 of 16 May 2014 amending Regulation (EC) No 401/2006 as regards methods of sampling of large lots, spices and food supplements, performance criteria for T-2, HT-2 toxin and citrinin and screening methods of analysis. Official Journal of the European Union L147: 29-43.

Fung, F. and Clark, R.F., 2004. Health effects of mycotoxins: a toxicological overview. Clinical Toxicology 42: 217-234.

Furey, A., Moriarty, M., Bane, V., Kinsella, B. and Lehane, M.,2013. Ion suppression; A critical review on causes, evaluation, prevention and applications. Talanta 115: 104-122.

Gonzalez-Antuna, A., Dominguez-Romero, J.C., Garcia-Reyes, J.F., Rodriguez-Gonzalez, P., Centineo, G., Garcia Alonso, J.I. and Molina-Diaz, A., 2013. Overcoming matrix effects in electrospray: quantitation of $\beta$-agonists in complex matrices by isotope dilution liquid chromatography-mass spectrometry using singly (13) C-labeled analogues. Journal of Chromatography A 1288: 40-47.

Gonzalez-Antuna, A., Rodriguez-Gonzalez, P., Centineo, G. And Garcia Alonso, J.I., 2010. Evaluation of minimal 13C-labelling for stable isotope dilution in organic analysis. Analyst 135: 953-964.

Hewavitharana, A.K., 2011. Matrix matching in liquid chromatography - mass spectrometry with stable isotope labelled internal standards - is it necessary ? Journal of Chromatography A 1218: 359361.

Malachova, A., Sulyok, M., Beltran, E., Berthiller, F. and Krska, R., 2014. Optimization and validation of a quantitative líquid chromatography-tandem mass spectrometric method covering 295 bacterial and fungal metabolites including all regulated mycotoxins in four model food matrices. Journal of Chromatography A 1362: 145-156.

Matuszewski, B.K. and Constanzer, M.L., 2003. Strategies for the assessment of matrix effect in quantitative bioanalytical methods based on HPLC-MS/MS. Analytical Chemistry 75: 3019-3030.

Pascale, M., 2009. Detection methods for mycotoxins in cereal grains

and cereal products. Zbornik Matice srpske za prirodne nauke

117: 15-25.

Peters, F.T. and Maurer, H.H., 2007. Systematic comparison of bias and precision data obtained with multiple-point and one-point calibration in six validated multianalyte assays for quantification of drugs in human plasma. Analytical Chemistry 79: 4967-4976.

Ramaley, L. and Cubero Herrera, L., 2008. Software for the calculation of isotope patterns in tandem mass spectrometry. Rapid Communications in Mass Spectrometry 22: 2707-2714.

Roland, A., Bros P., Bouisseau, A., Cavelier, F. and Schneider, R., 2014. Analysis of Ochratoxin A in grapes, musts and wines by LC-MS/MS: first comparison of stable isotope dilution assay and diastereomèric dilution assay methods. Analytica Chimica Acta 818: 39-45. 
Shephard, G.S., Berthiller, F., Burdaspal, P.A., Crews, C., Jonker, M.A., Krska, R., Lattanzio, V.M.T., MacDonald, S., Malone, R.J., Maragos, C., Sabino, M., Solfrizzo, M., Van Egmond, H.P. and Whitaker, T.B., 2013. Developments in mycotoxin analysis: an update for 2011-2012. World Mycotoxin Journal 6: 3-30.

Stahnke, H., Kittlaus, S., Kempe, G. and Alder, L., 2012. Reduction of matrix effects in liquid chromatography-electrospray ionizationmass spectrometry by dilution of the sample extracts: how much

dilution is needed? Analytical Chemistry 84: 1474-1482.

Stahnke, H., Reemtsma, T. and Alder L., 2009. Compensation of matrix effects by postcolumn infusion of a monitor substance in multiresidue analysis with LC-MS/MS. Analytical Chemistry 81: 2185-2192.

Taylor, P.J., 2005. Matrix effects: the Achilles heel of quantitative high-performance liquid chromatography-electrospray-tandem mass spectrometry. Clinical Biochemistry 38: 328-334.

Trufelli, H., Palma, P., Famiglini, G. and Cappiello, A., 2011. An overview of matrix effects in liquid chromatography-mass spectrometry. Mass Spectrometry Reviews 30: 491-509.

Varga, E., Glauner, T., Koppen, R., Mayer, K., Sulyok, M., Schuhmacher, R., Krska, R. and Berthiller, F., 2012. Stable isotope dilution assay for the accurate determination of mycotoxins in maize by UHPLCMS/ MS. Analytical and Bioanalytical Chemistry 402: 2675-2686.

\section{Supplemental Information}

Table S - 1. Name, selected reaction monitoring (SRM) transition and formula for precursor for the natural and isotopically labelled mycotoxin.

\begin{tabular}{|c|c|c|c|c|}
\hline \multirow[b]{2}{*}{ Name } & \multicolumn{2}{|l|}{ SRM transition } & \multirow[b]{2}{*}{ Precursor ion } & \multirow[b]{2}{*}{ Product ion } \\
\hline & Natural & U-Labelled $^{1}$ & & \\
\hline Deoxynivalenol (ESI+) & $297.0>249.1$ & $312.0>263.1$ & {$\left[\mathrm{C}_{15} \mathrm{H}_{20} \mathrm{O}_{6}+\mathrm{H}\right]^{+}$} & {$\left[\mathrm{C}_{14} \mathrm{H}_{16} \mathrm{O}_{4}+\mathrm{H}\right]^{+}$} \\
\hline Aflatoxin $\mathrm{B}_{1}(\mathrm{ESI}+)$ & $313.1>285.1$ & $330.1>301.1$ & {$\left[\mathrm{C}_{17} \mathrm{H}_{12} \mathrm{O}_{6}+\mathrm{H}\right]^{+}$} & {$\left[\mathrm{C}_{16} \mathrm{H}_{12} \mathrm{O}_{5}+\mathrm{H}\right]^{+}$} \\
\hline HT-2 Toxin(ESI+) & $442.2>263.1$ & $464.2>278.1$ & {$\left[\mathrm{C}_{22} \mathrm{H}_{32} \mathrm{O}_{8}+\mathrm{NH}_{4}\right]^{+}$} & {$\left[\mathrm{C}_{15} \mathrm{H}_{17} \mathrm{O}_{3}+\mathrm{NH}_{4}\right]^{+}$} \\
\hline Fumonisin $\mathrm{B}_{1}(\mathrm{ESI}+)$ & $722.2>334.2$ & $756.2>356.2$ & {$\left[\mathrm{C}_{34} \mathrm{H}_{59} \mathrm{NO}_{15}+\mathrm{H}\right]^{+}$} & {$\left[\mathrm{C}_{22} \mathrm{H}_{39} \mathrm{NO}+\mathrm{H}\right]^{+}$} \\
\hline T-2 Toxin (ESI+) & $484.2>185.1$ & $508.2>198.1$ & {$\left[\mathrm{C}_{24} \mathrm{H}_{34} \mathrm{O}_{9}+\mathrm{NH}_{4}\right]^{+}$} & {$\left[\mathrm{C}_{13} \mathrm{H}_{11}+\mathrm{NH}_{4}\right]^{+}$} \\
\hline Fumonisin $\mathrm{B}_{3}(\mathrm{ESI}+)$ & $706.2>336.2$ & $740.2>358.2$ & {$\left[\mathrm{C}_{34} \mathrm{H}_{59} \mathrm{NO}_{14}+\mathrm{H}\right]^{+}$} & {$\left[\mathrm{C}_{22} \mathrm{H}_{41} \mathrm{NO}+\mathrm{H}\right]^{+}$} \\
\hline Fumonisin $\mathrm{B}_{2}(\mathrm{ESI}+)$ & $706.2>336.2$ & $740.2>358.2$ & {$\left[\mathrm{C}_{34} \mathrm{H}_{59} \mathrm{NO}_{14}+\mathrm{H}\right]^{+}$} & {$\left[\mathrm{C}_{22} \mathrm{H}_{41} \mathrm{NO}+\mathrm{H}\right]^{+}$} \\
\hline Ochratoxin A (ESI+) & $404.2>239.1$ & $424.2>250.1$ & {$\left[\mathrm{C}_{20} \mathrm{H}_{18} \mathrm{Cl} \mathrm{NO}{ }_{6}+\mathrm{H}\right]^{+}$} & {$\left[\mathrm{C}_{11} \mathrm{H}_{8} \mathrm{ClO}_{4}+\mathrm{H}\right]^{+}$} \\
\hline Zearalenone (ESI+) & $319.3>283$ & $337.3>301$ & {$\left[\mathrm{C}_{18} \mathrm{H}_{22} \mathrm{O}_{5}+\mathrm{H}\right]^{+}$} & {$\left[\mathrm{C}_{18} \mathrm{H}_{18} \mathrm{O}_{3}+\mathrm{H}\right]^{+}$} \\
\hline Zearalenone (ESI-) & $317.1>175.1$ & $335.1>185.1$ & {$\left[\mathrm{C}_{18} \mathrm{H}_{21} \mathrm{O}_{5}\right]^{-}$} & {$\left[\mathrm{C}_{10} \mathrm{H}_{18} \mathrm{O}_{3}\right]^{-}$} \\
\hline
\end{tabular}

${ }^{1} \mathrm{U}$-labelled stands for uniformly ${ }^{13} \mathrm{C}$-labelled mycotoxins 
Table S -2. Concentration obtained in positive samples by single-level standard addition.

\begin{tabular}{|c|c|c|c|c|c|}
\hline Compound & Maize (mg/Kg) & $\begin{array}{l}\text { Compound } \\
\text { feed (mg/Kg) }\end{array}$ & Straw (mg/Kg) & $\begin{array}{l}\text { Nutmeg } \\
\text { (mg/Kg) }\end{array}$ & $\begin{array}{l}\text { Curcuma } \\
\text { (mg/Kg) }\end{array}$ \\
\hline Deoxynivalenol & $0.15 \pm 0.04$ & $0.17 \pm 0.06$ & $1.05 \pm 0.15$ & n.d. & n.d. \\
\hline Aflatoxin $B_{1}$ & n.d. & n.d. & n.d. & n.d. & n.d. \\
\hline HT-2 toxin & $0.022 \pm 0.010$ & n.d. & n.d. & n.d. & n.d. \\
\hline Fumonisin $B_{1}$ & $0.67 \pm 0.17$ & $0.15 \pm 0.03$ & n.d. & n.d. & n.d. \\
\hline $\mathrm{T}-2$ toxin & $0.013 \pm 0.005$ & n.d. & n.d. & n.d. & n.d. n.d. \\
\hline Fumonisin $B_{3}$ & $0.046 \pm 0.016$ & n.d. & n.d. & n.d. & n.d. \\
\hline Fumonisin $B_{2}$ & $0.13 \pm 0.03$ & $0.056 \pm 0.009$ & n.d. & n.d. & n.d. \\
\hline Ochratoxin A & n.d. & n.d. & n.d. & n.d. & n.d. \\
\hline Zearalenone & n.d. & n.d. & n.d. & n.d. & $0.11 \pm 0.03$ \\
\hline
\end{tabular}


Table S - 3. Matrix effect and recoveries in percentage of mycotoxins in compound feed using different calibration approaches.

\begin{tabular}{|c|c|c|c|c|c|c|c|c|c|}
\hline \multirow[b]{3}{*}{ Compound } & \multirow[b]{3}{*}{ Matrix effect $\pm S D$} & \multicolumn{3}{|c|}{ Multi-level calibration } & \multicolumn{5}{|c|}{ Single-level calibration } \\
\hline & & \multirow[b]{2}{*}{$\begin{array}{l}\text { Solvent STD } \\
\text { w/o IL-IS }\end{array}$} & \multirow[b]{2}{*}{$\begin{array}{l}\text { Solvent STD } \\
\text { with IL-IS }\end{array}$} & \multicolumn{4}{|c|}{ Standard addition } & \multicolumn{2}{|c|}{ Internal calibration } \\
\hline & & & & L1-L3 & L1 & L2 & L3 & OPIC & IPD \\
\hline & & \multicolumn{8}{|c|}{ Recovery (RSD) $n=3$, three different days) } \\
\hline Deoxynivalenol & $-58 \pm 6$ & $42(14)$ & $101(10)$ & $97(7)$ & $113(25)$ & $102(5)$ & $96(12)$ & $112(4)$ & $105(4)$ \\
\hline Aflatoxin $B_{1}$ & $-37 \pm 11$ & $63(16)$ & $105(19)$ & $92(8)$ & $104(38)$ & $100(14)$ & $94(7)$ & $103(13)$ & $110(14)$ \\
\hline HT-2 toxin & $5 \pm 20$ & $103(6)$ & $113(17)$ & $92(10)$ & $117(17)$ & $108(14)$ & $97(7)$ & $107(16)$ & $118(14)$ \\
\hline Fumonisin $B_{1}$ & $-6 \pm 22$ & $73(21)$ & $85(18)$ & $81(5)$ & 79 (18) & 79 (9) & $73(8)$ & $104(12)$ & $95(12)$ \\
\hline $\mathrm{T}-2$ toxin & $-10 \pm 21$ & $100(23)$ & $111(16)$ & $98(16)$ & $111(52)$ & $114(29)$ & $99(20)$ & $126(17)$ & $112(17)$ \\
\hline Fumonisin $\mathrm{B}_{3}$ & $-10 \pm 15$ & $93(24)$ & $101(26)$ & $81(11)$ & $111(38)$ & $101(12)$ & $84(15)$ & $119(3)$ & $106(2)$ \\
\hline Fumonisin $B_{2}$ & $1 \pm 5$ & $93(19)$ & $86(14)$ & $89(9)$ & $92(13)$ & $92(13)$ & $84(15)$ & $111(16)$ & $107(15)$ \\
\hline Ochratoxin A & $-12 \pm 15$ & $108(10)$ & $116(35)$ & $77(4)$ & $486(117)$ & $107(6)$ & 90 (14) & $129(24)$ & $134(23)$ \\
\hline Zearalenone & $-11 \pm 16$ & $92(18)$ & $95(16)$ & 95 (14) & $106(26)$ & $109(8)$ & $95(13)$ & $97(12)$ & $98(12)$ \\
\hline
\end{tabular}

aFigures in bold: recoveries or RSDr outside range EU 519/2014.

STD = standard, IL-IS = isotopically labelled internal standard; L1-L3 standard addition levels (see Experimental); ICAL: Isotopic Internal Calibration, IPD: Isotope Pattern Deconvolution. 
Table S - 4. Matrix effect and recoveries in percentage of mycotoxins in wheat straw using different calibration approaches.

\begin{tabular}{|c|c|c|c|c|c|c|c|c|c|}
\hline \multirow[b]{3}{*}{ Compound } & \multirow[b]{3}{*}{ Matrix effect $\pm S D$} & \multicolumn{3}{|c|}{ Multi-level calibration } & \multicolumn{5}{|c|}{ Single-level calibration } \\
\hline & & \multirow[b]{2}{*}{$\begin{array}{l}\text { Solvent STD } \\
\text { w/o IL-IS }\end{array}$} & \multirow[b]{2}{*}{$\begin{array}{l}\text { Solvent STD } \\
\text { with IL-IS }\end{array}$} & \multicolumn{4}{|c|}{ Standard addition } & \multicolumn{2}{|c|}{ Internal calibration } \\
\hline & & & & L1-L3 & L1 & L2 & L3 & OPIC & IPD \\
\hline & & \multicolumn{8}{|c|}{ Recovery (RSD) $n=3$, three different days) } \\
\hline Deoxynivalenol & $-39 \pm 12$ & $72(35)$ & $103(27)$ & $120(28)$ & $114(9)$ & $109(16)$ & $109(21)$ & $116(29)$ & $108(29)$ \\
\hline Aflatoxin $B_{1}$ & $-67 \pm 5$ & $44(19)$ & $120(16)$ & $122(7)$ & $119(34)$ & $127(18)$ & $122(14)$ & $116(19)$ & $125(19)$ \\
\hline HT-2 toxin & $1 \pm 12$ & $117(22)$ & $108(4)$ & $106(8)$ & $136(25)$ & $114(7)$ & $108(10)$ & $106(9)$ & $118(9)$ \\
\hline Fumonisin $\mathrm{B}_{1}$ & $3 \pm 10$ & $107(20)$ & $121(20)$ & $96(23)$ & $102(22)$ & $97(9)$ & $95(11)$ & $144(6)$ & $131(6)$ \\
\hline $\mathrm{T}-2$ toxin & $-26 \pm 6$ & $92(20)$ & $103(8)$ & $114(9)$ & $130(33)$ & $113(3)$ & $114(8)$ & $126(12)$ & $112(13)$ \\
\hline Fumonisin $\mathrm{B}_{3}$ & $-1 \pm 9$ & $113(28)$ & $102(41)$ & $97(15)$ & $95(21)$ & $104(20)$ & $98(17)$ & $126(3)$ & $114(3)$ \\
\hline Fumonisin $B_{2}$ & $0 \pm 10$ & $128(24)$ & $119(14)$ & $101(14)$ & $143(19)$ & $117(20)$ & $111(16)$ & $145(22)$ & $138(21)$ \\
\hline Ochratoxin $A^{b}$ & $-16 \pm 15$ & $117(30)$ & $98(10)$ & - & - & - & - & $121(18)$ & $128(14)$ \\
\hline Zearalenone & $-15 \pm 17$ & $109(18)$ & $89(13)$ & $127(21)$ & $137(41)$ & $125(3)$ & $123(8)$ & $95(18)$ & $97(18)$ \\
\hline
\end{tabular}

aFigures in bold: recoveries or RSDr outside range EU 519/2014. bUnsatisfactory linearity were obtained for standard addition method

STD = standard, IL-IS = isotopically labelled internal standard; L1-L3 standard addition levels (see Experimental); ICAL: Isotopic Internal Calibration, IPD: Isotope Pattern Deconvolution. 
Table S -5. Matrix effect and recoveries in percentage of mycotoxins in curcuma using different calibration approaches.

\begin{tabular}{|c|c|c|c|c|c|c|c|c|c|}
\hline \multirow[b]{3}{*}{ Compound } & \multirow[b]{3}{*}{ Matrix effect $\pm S D$} & \multicolumn{3}{|c|}{ Multi-level calibration } & \multicolumn{5}{|c|}{ Single-level calibration } \\
\hline & & \multirow[b]{2}{*}{$\begin{array}{l}\text { Solvent STD } \\
\text { w/o IL-IS }\end{array}$} & \multirow[b]{2}{*}{$\begin{array}{l}\text { Solvent STD } \\
\text { with IL-IS }\end{array}$} & \multicolumn{4}{|c|}{ Standard addition } & \multicolumn{2}{|c|}{ Internal calibration } \\
\hline & & & & L1-L3 & L1 & L2 & L3 & OPIC & IPD \\
\hline & & \multicolumn{8}{|c|}{ Recovery (RSD) $n=3$, three different days) } \\
\hline Deoxynivalenol & $-42 \pm 5$ & $56(11)$ & $95(10)$ & $92(9)$ & $104(22)$ & $99(5)$ & $95(2)$ & $108(16)$ & $100(16)$ \\
\hline Aflatoxin $B_{1}$ & $-85 \pm 1$ & $13(26)$ & $107(26)$ & $100(19)$ & $69(29)$ & $88(18)$ & $92(23)$ & $111(39)$ & $119(36)$ \\
\hline HT-2 toxin & $-26 \pm 12$ & $56(17)$ & $101(20)$ & $91(16)$ & $81(53)$ & $84(36)$ & $86(28)$ & $96(14)$ & $106(13)$ \\
\hline Fumonisin $B_{1}$ & $-9 \pm 9$ & $82(15)$ & $65(35)$ & $77(13)$ & $102(30)$ & $92(13)$ & $84(15)$ & $84(29)$ & $77(29)$ \\
\hline $\mathrm{T}-2$ toxin & $-65 \pm 1$ & $36(6)$ & $88(6)$ & $97(13)$ & $100(39)$ & $107(9)$ & $97(9)$ & $102(6)$ & $91(6)$ \\
\hline Fumonisin $B_{3}$ & $-11 \pm 12$ & $80(10)$ & $86(35)$ & $85(25)$ & $101(25)$ & $89(7)$ & $88(12)$ & $109(28)$ & $99(29)$ \\
\hline Fumonisin $B_{2}$ & $-6 \pm 9$ & $91(11)$ & $80(34)$ & $94(11)$ & $120(17)$ & $98(3)$ & 99 (9) & 95 (37) & $90(37)$ \\
\hline Ochratoxin A & $-76 \pm 11$ & $21(20)$ & $92(18)$ & - & - & - & - & $84(48)$ & $-c$ \\
\hline Zearalenone & $-89 \pm 4$ & $6(34)$ & $77(11)$ & $82(4)$ & $86(22)$ & $76(12)$ & $77(7)$ & $96(11)$ & $100(11)$ \\
\hline
\end{tabular}

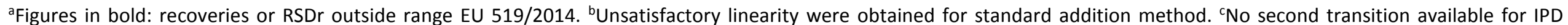
calculations.

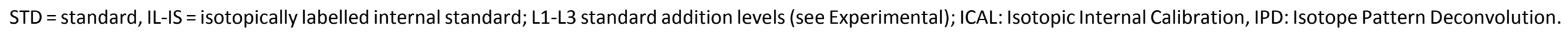




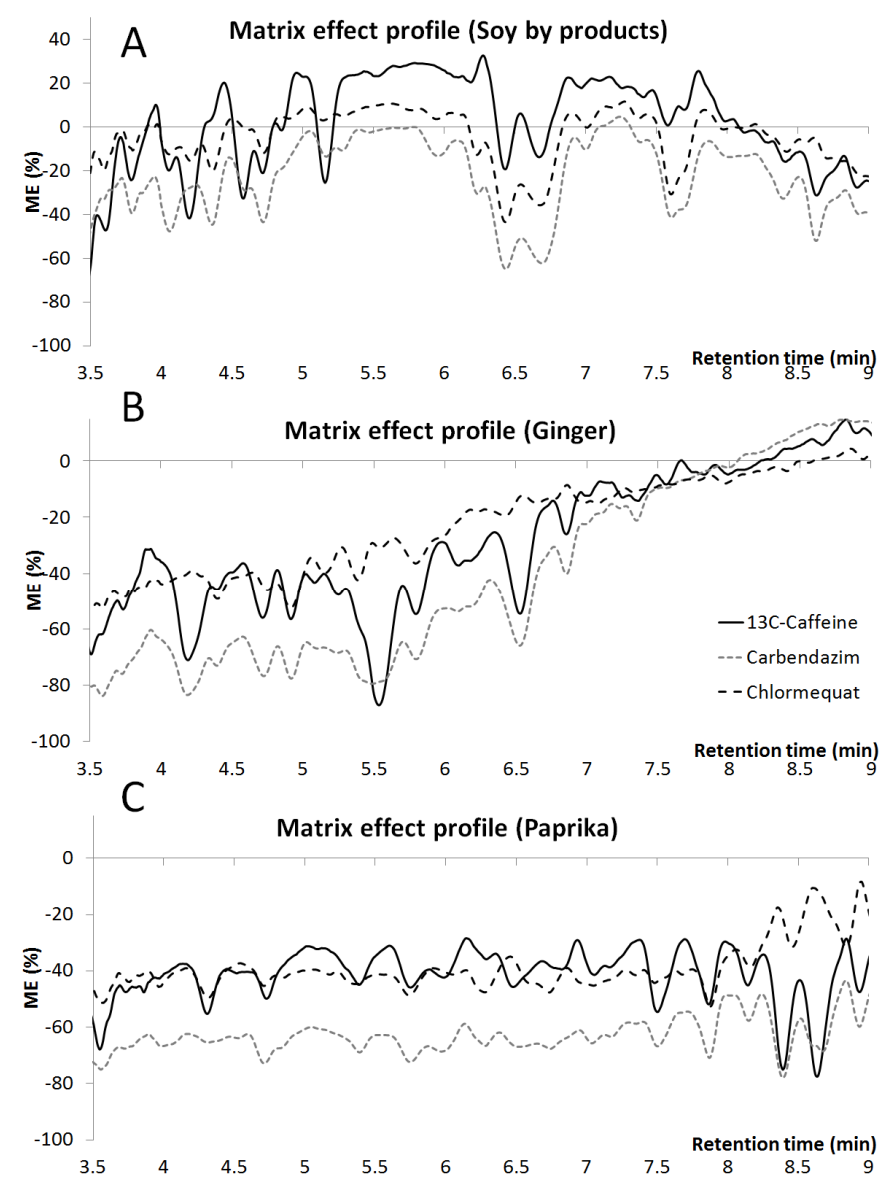

Figure S - 1. Matrix effect profile for (A) soy by-products, (B) ginger and (C) paprika. 